\title{
Comparison of Modern Stroke Thrombectomy Approaches Using an In Vitro Cerebrovascular Occlusion Model
}

\author{
M. Mokin, S.V. Setlur Nagesh, C.N. Ionita, E.I. Levy, and A.H. Siddiqui
}

\begin{abstract}
BACKGROUND AND PURPOSE: A new in vitro cerebrovascular occlusion model of the intracranial circulation was developed recently for testing thrombectomy devices. Using this model, we compared recanalization success associated with different modern endovascular thrombectomy approaches.
\end{abstract}

MATERIALS AND METHODS: Model experiments were performed in 4 thrombectomy test groups: 1) primary or direct Stentriever thrombectomy with a conventional guide catheter (control group), 2) primary Stentriever thrombectomy with a balloon-guide catheter, 3) combined Stentriever-continuous aspiration approach, and 4) direct aspiration alone. Successful recanalization was defined as a TICI score of $2 b$ or 3 .

RESULTS: Seventy-one thrombectomy experiments were conducted. Similar rates of $\mathrm{TICl} 2 \mathrm{~b}-3$ scores were achieved with balloon-guide and conventional guide catheters $(P=.34)$. The combined Stentriever plus aspiration approach and the primary aspiration thrombectomy resulted in significantly higher rates of $\mathrm{TICl} 2 \mathrm{~b}$ or 3 than the conventional guide-catheter approach in the control group $(P=.008$ and $P=$ .0001 , respectively). The primary Stentriever thrombectomy with the conventional guide catheter showed the highest rate of embolization to new territories (53\%).

CONCLUSIONS: Data from our in vitro model experiments show that the Stentriever thrombectomy under continuous aspiration and primary aspiration thrombectomy approaches led to the highest degree of recanalization.

ABBREVIATIONS: ADAPT = direct aspiration first pass technique; EDT = embolization in distal territory; ENT = embolization in new territory; SWIFT = Solitaire FR With the Intention for Thrombectomy; TREVO 2 = Thrombectomy REvascularization of large Vessel Occlusions in acute ischemic stroke

S ince the publication of the Solitaire FR With the Intention for Thrombectomy (SWIFT) and Thrombectomy REvascularization of large Vessel Occlusions in acute ischemic stroke (TREVO 2) randomized clinical trials, Stentrievers (Trevo; Stryker, Kalamazoo, Michigan) have become widely used for endovascular treatment of stroke. ${ }^{1,2}$ Postmarketing experience

Received June 22, 2014; accepted after revision September 6 .

From the Departments of Neurosurgery (M.M., E.I.L., A.H.S.), Biomedical Engineering (S.V.S.N., C.N.I.), Electrical Engineering (S.V.S.N.), Mechanical and Aerospace Engineering (S.V.S.N.), and Radiology (E.I.L., A.H.S.) and Toshiba Stroke and Vascular Research Center (C.N.I., E.I.L., A.H.S.), University at Buffalo, State University of New York, Buffalo, New York; and Jacobs Institute (A.H.S.), Buffalo, New York.

Devices were provided by Covidien, Stryker, and Penumbra. All data collection, analysis, and interpretation were performed by the authors, independent of company input or interpretation.

Please address correspondence to Adnan H. Siddiqui, MD, PhD, University at Buffalo Neurosurgery, 100 High St, Suite B4, Buffalo, NY 14203; e-mail: asiddiqui@ ubns.com

- Indicates open access to non-subscribers at www.ajnr.org

http://dx.doi.org/10.3174/ajnr.A4149 indicates that in modern clinical practice, Stentrievers are often used in conjunction with another device such as an aspiration thrombectomy catheter or a balloon-guide catheter. ${ }^{3-5}$ Moreover, direct aspiration thrombectomy by using recently developed large-bore aspiration catheters has shown promise as an effective alternative approach for intra-arterial revascularization. ${ }^{6,7}$ However, the recanalization effectiveness of these types of thrombectomy devices has not been compared in a randomized trial, to our knowledge.

A novel in vitro intracranial cerebrovascular occlusion model for testing thrombectomy devices was developed recently. ${ }^{8,9}$ This $3 \mathrm{D}$ printed model is uniquely constructed on the basis of patientspecific anatomies to mimic a typical intracranial circulation by the presence of robust collaterals through both anterior and posterior communicating arteries and the typical tortuosity encountered in the intracranial circulation. In addition, the modulus of the model is closer to normal physiologic vessels than typical silicone models, allowing a feel and device deformation that are similar to those in a real clinical situation. ${ }^{10,11}$ Here, we com- 

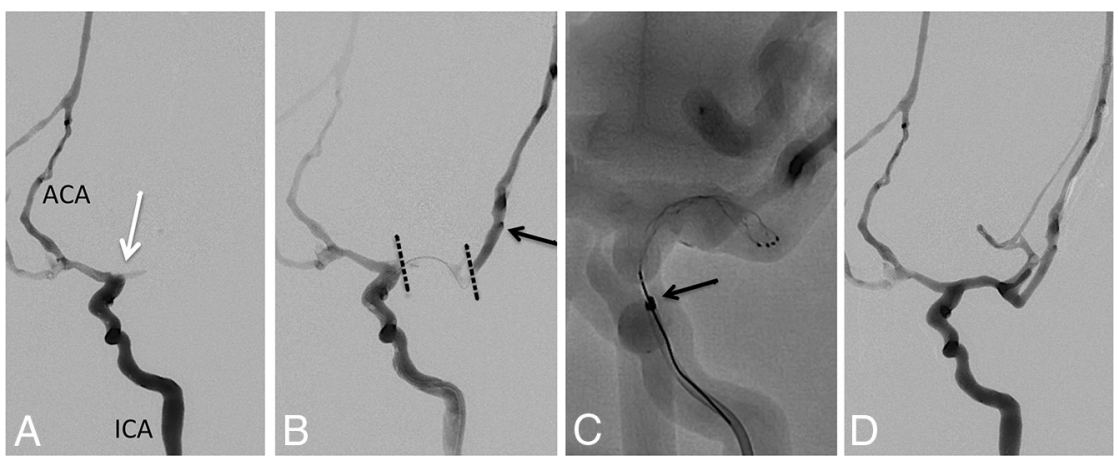

FIG 1. Combined Stentriever plus aspiration approach to thrombectomy. A, Baseline angiogram, anteroposterior view, left ICA injection, demonstrating occlusion at the MCA origin (white arrow). ACA indicates anterior cerebral artery. $B$, Combined left ICA and microcatheter injection shows the extent of the thrombus within the left MCA (dotted black lines). Black arrow points to the tip of the microcatheter within an M2 branch of the MCA. C, Solitaire FR stent retriever is deployed within the M1 MCA segment. Black arrow points to the distal tip of the 5MAX ACE reperfusion catheter. $D$, Final angiogram after successful thrombectomy shows robust filling of the left MCA branches except for some distal superior trunk vessels. The final recanalization grade is $\mathrm{TICl} 2 \mathrm{~b}$.

pare primary Stentriever thrombectomy with the aforementioned other modern thrombectomy approaches by using this in vitro model.

Ethics Statement. The collection of clinical data for the model design was approved by the University at Buffalo institutional review board.

\section{MATERIALS AND METHODS Model Description}

The in vitro model of the intracranial cerebrovascular occlusion has been described in detail previously. ${ }^{89}$ This model closely resembles the human intracranial circulation and consists of 3 separate inflow channels mimicking the basilar artery and the 2 intracranial ICA branches. The design includes the MCA branches (M1-M4 segments with the smallest vessels of $1 \mathrm{~mm}$ in diameter), bilateral A1 anterior cerebral artery segments connected to a single anterior cerebral artery, and a single posterior communicating artery (right side), allowing near-complete circle of Willis circulation. The circulating fluid $(40 \%$ glycerol, $60 \%$ water) was maintained at $37^{\circ} \mathrm{C}$. A pulsatile pump (Masterflex; Cole-Parmer, Vernon Hills, Illinois) was used to simulate cardiac output.

Fresh clots were prepared by mixing $4 \mathrm{~mL}$ of fresh swine blood (no anticoagulant), $32 \mathrm{mg}$ of fibrinogen from bovine plasma (Sigma-Aldrich, St. Louis, Missouri; catalog No. F8630), and 1 U of thrombin from bovine plasma (Sigma-Aldrich, catalog No. T4648) in a 5-mL syringe for at least 3 minutes. The mixture was placed into plastic tubing (4-mm-diameter) and incubated at room temperature for at least 60 minutes. Clots were then cut into 10 -mm-length pieces and were introduced into the flow loop through a $9 \mathrm{~F}$ sheath. The clots were navigated into the M1 or M2 MCA segment with anterograde flow of the circulatory fluid. Pressure measurements of the intracranial vessels by using the conventional guide catheter before and after clot introduction were reported in our initial publication describing the model. ${ }^{9}$ Inflation of the balloon-guide catheter resulted in a 3-mm Hg decrease in pressure immediately proximal to the clot.

\section{Thrombectomy Procedures}

After placing the clot into the target vessel (either the M1 or proximal M2 MCA segment), we performed baseline angiography injections to confirm the occlusion site. A single thrombectomy attempt was allowed for each experiment in the 4 groups described below.

The control group (group 1) consisted of thrombectomy cases performed by using a conventional guide catheter. For these experiments, we used a 6F Shuttle (Cook Medical, Bloomington, Indiana), which was placed into the segment corresponding to the cervical ICA. A 0.021-inch microcatheter was delivered over a 0.014 -inch wire to cross the clot under fluoroscopy and road-mapping guidance. A microinjection through the microcatheter was performed to document the extent of occlusion distally. A Solitaire FR device (Covidien, Irvine, California) or a Trevo ProVue Stentriever (Stryker) was delivered by using the 0.021 -inch microcatheter, deployed at the occlusion site, left in place for 5 minutes, and then retrieved.

For experiments testing the balloon-guide-catheter approach (group 2), thrombectomy was performed with an $8 \mathrm{~F}$ catheter (Concentric Medical, Mountain View, California) or an 8F Cello BalloonGuide Catheter (Covidien). The balloon was inflated before the Stentriever was withdrawn, and manual aspiration though the guide catheter was applied by using a 20 -mL syringe.

For experiments testing the combined Stentriever and aspiration approach (group 3), an intermediate catheter (5MAX ACE Reperfusion Catheter; Penumbra, Alameda, California) and the 6F Cook Shuttle were used. The Stentriever was withdrawn into the reperfusion catheter under continuous aspiration by using the Aspiration Pump (Penumbra). Figure 1 shows an example of this experiment.

For experiments testing the primary aspiration approach, no Stentriever was used (group 4). The 5MAX ACE catheter was delivered over the microcatheter (always attempting not to cross the clot with the microcatheter-microwire construct) and advanced to the level of the thrombus, according to the previously described direct aspiration first pass technique (ADAPT). ${ }^{6}$ Aspiration through the Penumbra Aspiration Pump was applied while the aspiration catheter was gently pushed forward to ensure complete contact with the clot. After 2 minutes of continuous aspiration, if no clot was collected, the aspiration catheter was withdrawn under continuous aspiration.

While performing thrombectomy, we continuously monitored the clot and thrombectomy devices via gross observation and high-definition video recording to document the location of any clot breakdown. Primary outcomes included the degree of recanalization (based on the TICI grading scale) and the occurrence of emboli. Successful recanalization was defined as a TICI score of $2 \mathrm{~b}$ or 3 . Embolization in new territory (ENT) was defined 


\begin{tabular}{|c|c|c|c|c|}
\hline & $\begin{array}{c}\text { Conventional Guide + } \\
\text { Stentriever }(n=19)\end{array}$ & $\begin{array}{c}\text { Balloon-Guide + } \\
\text { Stentriever }(n=20)\end{array}$ & $\begin{array}{c}\text { Stentriever }+ \\
\text { Aspiration }(n=17)\end{array}$ & $\begin{array}{c}\text { Direct } \\
\text { Aspiration }(n=15)\end{array}$ \\
\hline \multicolumn{5}{|l|}{$\mathrm{TICl}$ score } \\
\hline 0 (No.) (\%) & $7(37 \%)$ & $8(40 \%)$ & $0(0 \%)$ & $0(0 \%)$ \\
\hline 1 (No.) (\%) & $2(11 \%)$ & $0(0 \%)$ & $1(6 \%)$ & $0(0 \%)$ \\
\hline $2 a(N o).(\%)$ & $3(16 \%)$ & $1(5 \%)$ & $2(12 \%)$ & $0(0 \%)$ \\
\hline $2 b($ No.) $(\%)$ & $2(11 \%)$ & $3(15 \%)$ & $3(18 \%)$ & $2(13 \%)$ \\
\hline $3($ No.) $(\%)$ & $5(26 \%)$ & $8(40 \%)$ & $11(65 \%)$ & $13(87 \%)$ \\
\hline $2 b$ or 3 (No.) (\%) & $7(37 \%)$ & $11(55 \%)$ & $14(82 \%)$ & $15(100 \%)$ \\
\hline \multicolumn{5}{|l|}{ Embolic events } \\
\hline Embolization of new territories (No.) (\%) & $10(53 \%)$ & $2(10 \%)$ & $2(12 \%)$ & $0(0 \%)$ \\
\hline Embolization of distal territories (No.) (\%) & $3(16 \%)$ & $3(15 \%)$ & $4(24 \%)$ & $2(13 \%)$ \\
\hline
\end{tabular}
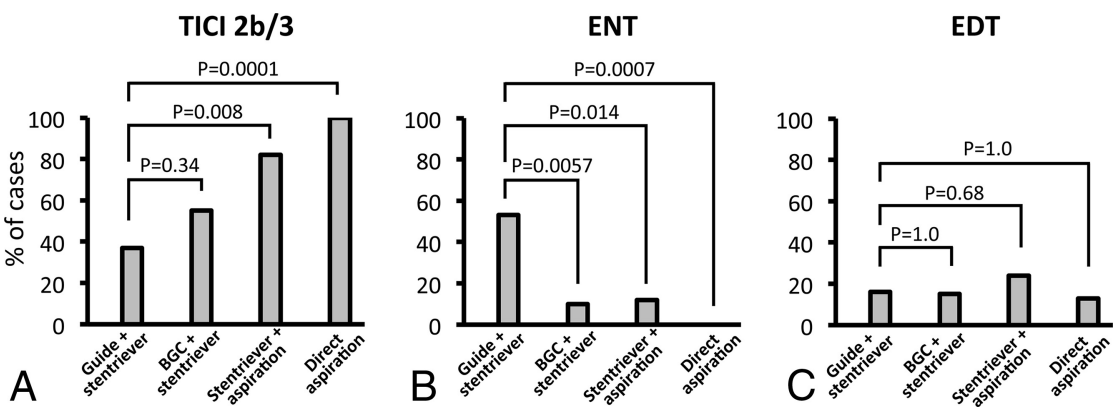

FIG 2. A, Rates of $\mathrm{TICl} 2 \mathrm{~b}$ or 3 recanalization achieved with different thrombectomy approaches. "Guide + Stentriever" represents the primary Stentriever approach by using a conventional guide catheter. "BGC + Stentriever" represents the primary Stentriever approach by using a balloonguide catheter. "Stentriever + aspiration" represents the combined Stentriever plus continuous aspiration approach. "Direct aspiration" represents thrombectomy performed by using the direct aspiration approach without the use of a Stentriever. $B$, Rates of embolization of new territories with different thrombectomy approaches. $C$, Rates of embolization of distal territories with different thrombectomy approaches.

as emboli observed on posthrombectomy angiography within previously unaffected territories. Embolization in distal territory (EDT) was defined as emboli seen within the territory of the vessel where the thrombus was originally placed. Final TICI scores and postthrombectomy embolic events were analyzed blinded to the type of thrombectomy approach.

\section{Statistical Analysis}

Analysis of variables was performed by using the Fisher exact test. $P<.05$ was statistically significant.

\section{RESULTS}

We conducted 71 thrombectomy experiments: 19 primary Stentriever thrombectomies by using a conventional guide catheter, 20 primary Stentriever thrombectomies by using a balloon-guide catheter, 17 combined Stentriever plus continuous aspiration thrombectomies, and 15 primary aspiration thrombectomies. The Table summarizes angiographic outcomes in each group. There was no significant difference in achieving TICI $2 b$ or 3 with a balloon-guide catheter versus a conventional catheter for primary Stentriever thrombectomy $(P=.34 ;$ Fig $2 A)$. The combined Stentriever plus continuous aspiration approach and primary aspiration thrombectomy resulted in significantly higher rates of TICI $2 \mathrm{~b}$ or 3 than the primary Stentriever thrombectomy with the conventional guide catheter $(P=.008$ and $P=.0001$, respectively; Fig 2A).

\section{DISCUSSION}

Our study showed that the highest degree of revascularization was achieved with the use of the combined Stentriever-aspiration thrombectomy or primary aspiration techniques. The use of the balloon-guide catheter for Stentriever thrombectomy did not result in significant improvement in recanalization, though a trend toward higher TICI scores was noted. Embolic events can occur in up to $12 \%$ of cases of Stentriever thrombectomy and are associated with a 2 -fold increase in mortality compared with cases without embolic complications. ${ }^{12}$ In our experiments, we observed the presence of substantial ENT with all approaches except for direct aspiration; however, regarding EDT events, no technique protects effectively from this occurrence.

Nguyen et $\mathrm{al}^{13}$ published their experience with the use of the balloon-guide catheter in conjunction with Solitaire FR stent retriever thrombectomy. Although TICI 3 recanalization was seen more often in cases in which the balloon-guide catheter was used (54\% with the balloon-guide catheter versus 33\% without; $P<$ .001 ), overall rates of TICI $2 \mathrm{~b}$ or 3 recanalization were similar (76\% with versus $71 \%$ without, $P=.3$ ). Occurrence of distal emboli or emboli in new territories was also similar. Of importance, the discharge NIHSS score and 3-month favorable clinical outcome were significantly higher in the balloon-guide catheter group. It is possible that with a higher number of thrombectomy experiments in our study, we could have achieved a significant difference in obtaining higher recanalization results with the bal- 
loon-guide catheter because a trend toward higher TICI $2 \mathrm{~b}-3$ was observed in this group.

Our in vitro results with direct aspiration or the combined Stentriever-aspiration approach are different from those of the real-world clinical experience. Direct aspiration alone resulted in TICI $2 \mathrm{~b}$ or 3 recanalization in $75 \%-78 \%$ of cases, whereas the addition of Stentrievers improved the rate of successful recanalization to $95 \%$, according to the 2 recent studies of the directaspiration approach to stroke thrombectomy. ${ }^{6,7}$ EDT prompting additional aspiration was noted in $16 \%$ of cases in the initial experience with direct aspiration. ${ }^{6}$ In the ADAPT FAST series, the rate of EDT was also high $(10 \%)$ but no cases of ENT were observed. ${ }^{7}$ In our model, the rate of TICI 2 b or 3 recanalization reached $100 \%$, which is remarkably higher than that previously reported in clinical data. However, the $13 \%$ EDT rate is similar to rates reported in the ADAPT and ADAPT FAST studies. Turk et $\mathrm{al}^{7}$ compared radiographic outcomes from the realworld experience in the ADAPT FAST, SWIFT, TREVO, and North American Solitaire Stent-Retriever Acute Stroke studies, which can further help readers when matching our model data to the clinical results.

Our results should be interpreted with caution. First, this model is likely representative of an embolic stroke-type of largevessel occlusion, in which aspiration thrombectomy could be highly effective. The design of the model did not simulate intracranial atherosclerosis, thrombotic plaque, or embolic debris from a ruptured extracranial plaque, for which a Stentriever rather than primary aspiration thrombectomy might be of more benefit. Approximately one-third of large-vessel-occlusion strokes are of noncardioembolic origin (eg, 31\% in TREVO $2^{1}$ ). Another limitation is that intimal damage or occlusion of perforators, which can be evaluated in animal stroke models with the use of different thrombectomy devices, cannot be tested in our in vitro model. ${ }^{14}$

Second, only a single thrombectomy attempt was performed in each experiment, whereas in clinical practice multiple thrombectomy attempts are often required to achieve recanalization. It would also be interesting to study how the mode of aspiration affects revascularization success in our model. Simon and Grey ${ }^{15}$ demonstrated that manual aspiration with syringes can provide a substantially higher dynamic pressure at the catheter tip than the Penumbra aspiration system. We are planning to investigate this finding in future experiments. Third, because the smallest MCA M4 branches in the model were $0.5 \mathrm{~mm}$ in diameter, we did not account for embolization that could have occurred with debris under that size, which could further affect our final TICI score interpretation.

\section{CONCLUSIONS}

Data from these experiments indicate that the Stentriever thrombectomy under continuous aspiration and primary aspiration thrombectomy approaches lead to the highest degree of recanalization. However, embolization in nonaffected territories and in distal territories remains a major issue, which could affect eventual clinical outcomes. Such data might prove helpful in clinical practice when estimating radiographic outcomes with different endovascular treatment approaches.

\section{ACKNOWLEDGMENTS}

The authors thank Stephen Rudin, $\mathrm{PhD}$, for guidance; Liza Pope, BS, for clot preparation; Paul H. Dressel, BFA, for illustration preparation; and Debra J. Zimmer, for editorial assistance.

Disclosures: Ciprian N. Ionita—RELATED: Grant: National Institutes of Health*; Other: grants from the National Institutes of Health (2RO1EB002873; for partial support of student and faculty) and Toshiba (equipment) in conjunction with the present study; UNRELATED: Grants/Grants Pending: National Institutes of Health.* Elad I. Levy_UNRELATED: Stock/Stock Options: shareholder/ownership interests in Intratech Medical, Mynx/Access Closure, Blockade Medical LLC; Other: National Principal Investigator on the Covidien US SWIFT PRIME Trials (no compensation involved); compensation from Abbott for carotid training for physicians. Maxim Mokin-UNRELATED: Grants/Grants Pending: Toshiba (stroke research grant).* Adnan H. Siddiqui-RELATED: Other: Covidien, Stryker, Penumbra, Comments: Devices were provided by Covidien, Stryker, and Penumbra, Inc. All data collection, analysis, and interpretation were performed by the authors, independent of company input or interpretation; UNRELATED: Board Membership: Codman \& Shurtleff, Covidien Neurovascular, Comments: Advisory Board member; Consultancy: Codman \& Shurtleff, Concentric Medical, ev3/Covidien, Guidepoint Global Consulting, Penumbra, Stryker, Pulsar Vascular, MicroVention, Lazarus Effect, Blockade Medical; Grants/Grants Pending: National Institutes of Health (coinvestigator: National Institute of Neurological Disorders and Stroke 1RO1NS064592-01A1; National Institute of Biomedical Imaging and Bioengineering 5RO1EB002873-07), University at Buffalo (Research Development Award), Comments: research grants; Payment for Lectures (including service on Speakers Bureaus): Codman \& Shurtleff (Speakers Bureau and honoraria), Abbott Vascular (honoraria), Penumbra (honoraria); Stock/Stock Options: Hotspur Technologies, Intratech Medical, StimSox, Valor Medical, Blockade Medical, Lazarus Effect, Comments: financial interests; Other: Penumbra, Covidien, MicroVention, Comments: National Steering Committee member for Separator 3D Trial of Penumbra; SWIFT PRIME trial of Covidien, and FRED trial of MicroVention. No compensation. *Money paid to the institution.

\section{REFERENCES}

1. Nogueira RG, Lutsep HL, Gupta R, et al. Trevo versus Merci retrievers for thrombectomy revascularisation of large vessel occlusions in acute ischaemic stroke (TREVO 2): a randomised trial. Lancet 2012;380:1231-40

2. Saver JL, Jahan R, Levy EI, et al. Solitaire flow restoration device versus the Merci Retriever in patients with acute ischaemic stroke (SWIFT): a randomised, parallel-group, non-inferiority trial. Lancet 2012;380:1241-49

3. Humphries W, Hoit D, Doss VT, et al. Distal aspiration with retrievable stent assisted thrombectomy for the treatment of acute ischemic stroke. J Neurointerv Surg 2015;7:90-94

4. Mokin M, Dumont TM, Veznedaroglu E, et al. Solitaire flow restoration thrombectomy for acute ischemic stroke: retrospective multicenter analysis of early postmarket experience after FDA approval. Neurosurgery 2013;73:19-25; discussion 25-26

5. Zaidat OO, Castonguay AC, Gupta R, et al. North American Solitaire Stent Retriever Acute Stroke registry: post-marketing revascularization and clinical outcome results. J Neurointerv Surg 2014;6:584-88

6. Turk AS, Spiotta A, Frei D, et al. Initial clinical experience with the ADAPT technique: a direct aspiration first pass technique for stroke thrombectomy. J Neurointerv Surg 2014;6:231-37

7. Turk AS, Frei D, Fiorella D, et al. ADAPT FAST study: a direct aspiration first pass technique for acute stroke thrombectomy. J Neurointerv Surg 2014;6:260-64

8. Ionita CN, Mokin M, Varble N, et al. Challenges and limitations of patient-specific vascular phantom fabrication using 3D Polyjet printing. Proc SPIE 2014;9038:90380M

9. Mokin M, Ionita CN, Setlur Nagesh SV, et al. Primary stentriever versus combined stentriever plus aspiration thrombectomy approaches: in vitro stroke model comparison. J Neurointerv Surg 2014 Apr 30. [Epub ahead of print] 
10. Claes E, Atienza JM, Guinea GV, et al. Mechanical properties of human coronary arteries. Conf Proc IEEE Eng Med Biol Soc 2010; 2010:3792-95

11. Teng Z, Tang D, Zheng J, et al. An experimental study on the ultimate strength of the adventitia and media of human atherosclerotic carotid arteries in circumferential and axial directions. J Biomech 2009;42:2535-39

12. Gascou G, Lobotesis K, Machi P, et al. Stent retrievers in acute ischemic stroke: complications and failures during the perioperative period. AJNR Am J Neuroradiol 2014;35:734-40
13. Nguyen TN, Malisch T, Castonguay AC, et al. Balloon guide catheter improves revascularization and clinical outcomes with the Solitaire device: analysis of the North American Solitaire Acute Stroke Registry. Stroke 2014;45:141-45

14. Gralla J, Schroth G, Remonda L, et al. A dedicated animal model for mechanical thrombectomy in acute stroke. AJNR Am J Neuroradiol 2006;27:1357-61

15. Simon SD, Grey CP. Hydrodynamic comparison of the Penumbra system and commonly available syringes in forced-suction thrombectomy. J Neurointerv Surg 2014;6:205-11 